Original Article (short paper)

\title{
Prevalence and factors associated with sedentary behavior in the school recess among adolescents
}

\author{
Andressa Ferreira da Silva ${ }^{1}$ (1), Priscila Custódio Martins ${ }^{1}$ (1), Eliane Cristina de Andrade \\ Gonçalves $^{1}$ (1), Joni Marcio de Farias² $₫$, Diego Augusto Santos Silva ${ }^{1}$ (])
${ }^{1}$ Universidade Federal de Santa Catarina, UFSC, Research Center in Kinanthopometry and Human Performance, Florianópolis, SC, Brazil; ${ }^{2}$ Universidade do Extremo Sul Catarinense. Criciúma, SC, Brazil

\begin{abstract}
Aim: To estimate the prevalence of sedentary behavior in school recess and to verify sociodemographic factors (sex, age, economic level and type of school), anthropometric indicators (body mass index [BMI] and waist circumference) and lifestyle (level of physical activity and eating habits) associated with adolescents. Method: A crosssectional study with 583 adolescents (aged 11-17 years), from the city of Criciúma, Brazil. Sedentary behavior during school recess was self-reported. Sociodemographic and lifestyle information was obtained through a self-administered questionnaire. BMI was calculated and waist circumference was measured. Logistic regression was used to estimate odds ratios (OR) and 95\% confidence intervals (95\% CI). Results: The prevalence of sedentary behavior during school recess was 50.6\% (male 44.5\%, female 56.7\%). Adolescents aged 14-17 years (male [OR: 2.11, 95\% CI: 1.26-3.53], female [OR: $2.52,95 \%$ CI: 1.46-4.34]), from private schools (male [OR: 2.55, 95\% CI: 1.49-4.37], female [OR: 2.15, 95\% CI: 1.23-3.78]) were more likely to remain in sedentary behavior during school recess. Girls with high waist circumference (OR: $1.70 ; 95 \%$ CI: $1.01-2.84$ ) and inadequate eating habits (OR: $2.12 ; 95 \%$ CI: 1.05-4.24) were more likely to remain in sedentary behavior during school recess. Conclusion: Half of the adolescents presented sedentary behavior during school recess. Adolescents from private schools and in the age group of 14-17 years and girls with high waist circumference and inadequate eating habits were more likely to remain in sedentary behavior during school recess.
\end{abstract}

Keywords: adolescent health, sedentary lifestyle, lifestyle, students.

\section{Introduction}

Sedentary behavior can be defined as the time spent in activities with low energy expenditure, less than 1.5 metabolic equivalents (MET's), in a sitting or reclining position ${ }^{1,2}$. Systematic reviews have shown that sedentary behavior in children and adolescents was directly associated with reduced cardiorespiratory fitness, increased adiposity, and increased risk of developing metabolic syndrome in adulthood ${ }^{3,4}$. Although health problems associated with a sedentary lifestyle are evident, research developed in different regions of Brazil found a high prevalence of sedentary behavior in the pediatric population ${ }^{5-7}$.

Studies have shown that measuring the total time exposed to sedentary behaviors is not sufficient; we must also understand the pattern of this behavior, such as the existence of interruptions and the time of this pauses ${ }^{8}$. Small interruptions in sedentary behavior are beneficial to health and are favorably associated with metabolic markers, such as reduction of total cholesterol and triglyceride levels, and may also reflect higher total energy expenditure ${ }^{9,10}$. In this sense, school recess can be characterized as a moment for the interruption of sedentary behavior and for the practice of physical activities ${ }^{11,12}$.

Although school recess is a period of interruption of sedentary behavior at school, studies in other countries ${ }^{13,14}$ and in Brazil ${ }^{12,15}$ reported a high prevalence of sedentary behavior during school recess. In New Zealand, it was observed that
$73.6 \%$ of students were sedentary in the school recess ${ }^{13}$. In England, this prevalence was $59.3 \%{ }^{14}$. In Brazil, the prevalence found was $58.2 \%$ in the northeastern ${ }^{12}$ and $40.7 \%$ in the southern region of the country ${ }^{15}$.

Just as important as estimating the prevalence of sedentary behavior in school recess is to check the correlated factors. Studies have identified that sedentary behavior was associated with biological factors, such as sex and age, in which girls were more likely to be sedentary during school recess when compared to boys ${ }^{12,13,15}$ and students in the age group of 13-17 years were more likely to be sedentary during school recess when compared to younger adolescents ${ }^{12,13,15}$. Other factors that have been identified as correlated to daily sedentary behavior, such as economic status, lifestyle factors and body fat indicators 16-18 have been little investigated when it comes to sedentary behavior in school recess, which demonstrates the importance of these studies.

Thus, improving research to identify the groups most affected by such behavior during school recess may direct intervention strategies to reduce this behavior and increase the levels of physical activity of adolescents ${ }^{12}$. In addition, the investigation of sedentary behavior during recess can provide important information for the better planning of schools in relation to periods of sedentary behavior interruption as strategies for a more active recess ${ }^{15}$. Therefore, the aim of the present study was to estimate the prevalence of sedentary behavior in the school 
recess and to verify the socio-demographic factors (sex, age, economic level and type of school), anthropometric indicators (body mass index (BMI) and waist circumference) and lifestyle (level of physical activity and eating habits) of adolescents.

\section{Method}

This school-based cross-sectional epidemiological survey was conducted in the second half of 2015 in the city of Criciúma, Santa Catarina. The study was approved by the Ethics Committee for Research with Humans of the "Extremo Sul Catarinense" University (protocol No. 1.125.725. June 26, 2015). It is part of the "Association between health status, risk behaviors and level of physical activity of public school students in the City of Criciúma (SC)" research. Adolescents who participated in the research signed the Assent Term and parents/guardians signed the Free and Informed Consent Form, authorizing the participation of students in the research.

\section{Population and sample}

The sampling process was conducted in two stages: stratified by schools (private and public) and conglomerate of classes considering school grade. The sample size was determined for a finite population. The study included a population of 17,000 students in 49 eligible schools (six private schools and 43 public schools) and 670 classes from the 5 th grade of elementary schools to the 3 rd grade of high schools. In order to calculate the sample size of the macro project, overweight, low level of physical activity and low level of aerobic fitness were considered as the main outcomes. Considering the previous publications in the city of Criciúma ${ }^{19,20}$, the prevalence of $30 \%$ (overweight) or $70 \%$ (low levels of physical activity and low levels of aerobic fitness) were estimated for these outcomes. The confidence level adopted was $95 \%$, error estimated at five percentage points, a design effect of 1.5 and an increment of $20 \%$ for eventual losses and refusals. Considering these parameters, a sample of 570 students was estimated. Due to the class conglomerate process in which all data from students in selected classes were collected, the total sample was 583 students. To achieve this sample size, 24 classes (from two private schools and six public schools) were drawn because we considered that the class was formed by 25 students.

The following inclusion criteria were used in the study: (a) students aged 10 to 17 years, (b) absence of health problems that would prevent them from performing physical tests and anthropometric measures. Teens who refused to participate and those who did not have the consent signed by the parents or guardians were considered as refusals. Four students refused to take measurements of waist circumference (Figure 1).

Figure 1. Flowchart of the sampling process of the present study.

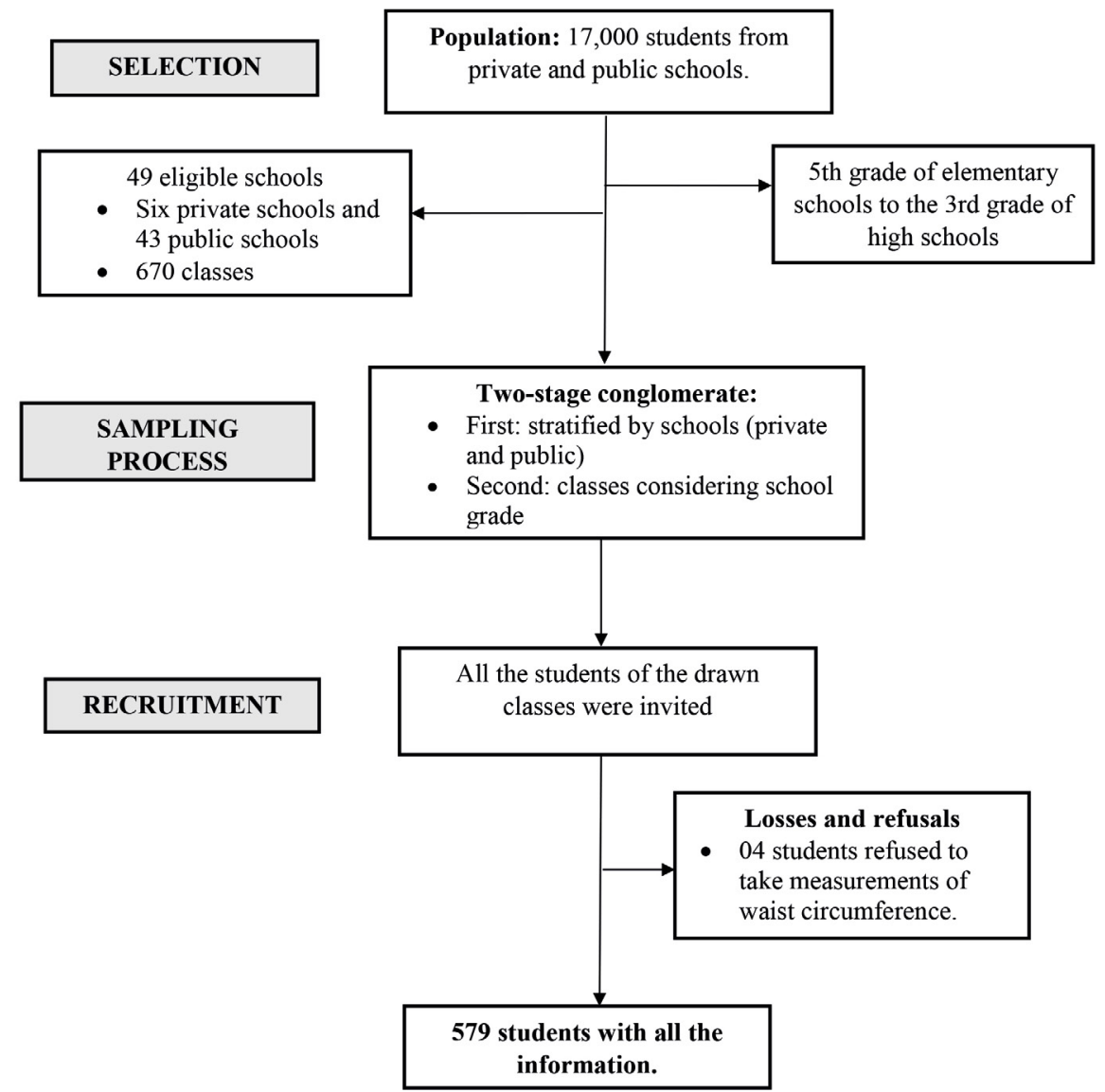




\section{Dependent variable}

Sedentary behavior during school recess was evaluated through the Physical Activity Questionnaire for Older Children (PAQ-C), validated and translated into the Portuguese language ${ }^{21}$. The question used was: "In the last 7 days, what have you done for most of the school recess or break?" This item presented as answer options: 1) remained seating, (talking, reading, or doing homework; 2) stood, stopped or walked; 3 ) ran or played a little; 4) ran or played quite a bit; 5) ran or played intensely. The results were categorized as "yes" (sedentary behavior), when the adolescent responded option 1. Adolescents who "did not" present sedentary behavior were those who answered options $2,3,4$ or 5 . This cutoff point was used to understand that the response options have an increasing order of physical activity practice since students can only choose one response option ${ }^{12}$.

\section{Independent variables}

Independent variables were the socio-demographic indicators (sex, age, economic level and type of school), anthropometric indicators (BMI and waist circumference), and lifestyle (physical activity and eating habits). Sex, age, economic level and type of school were collected through a self-administered questionnaire. Sex was categorized as "male" and "female"; age was collected in complete years and later dichotomized into "11 to 13 " and "14 to 17" years. Economic level was estimated by the Brazilian Association of Research Companies (ABEP) questionnaire and categorized as high (“A1", "A2", "B1", "B2") and low (“C1", "C2" "D" and "E"). Type of school was categorized as "public" or "private."

BMI uses body mass and height to identify weight status. Stature was collected through a Sanny ${ }^{\circledR}$ stadiometer (São Paulo, Brazil) and body mass through G-tech ${ }^{\circledR}$ digital scale (Zhongshan, China). In order to classify results in relation to BMI, the Z-score cutoffs proposed by the World Health Organization ${ }^{22}$ were used, in which the definition of overweight is $>+1$ standard deviation and obesity is $>+2$ standard deviations. In the present study, students, rated above $>+1$ standard deviation were considered as "overweight" and those below this value as "normal weight".

Waist circumference was measured in the narrower portion of the trunk, between the lower costal border and the iliac crest, with a Sanny ${ }^{\circledR}$ anthropometric tape (São Paulo, Brazil). To classify adolescents with abdominal obesity, the cutoff points previously proposed were used for children and adolescents, defining as excess abdominal obesity values with $Z$ score $\geq 1$. These cutoff points vary according to age and $\operatorname{sex}^{23}$.

Physical activity was assessed by the Brazilian version of the Youth Risk Behavior Surveillance System (YRBSS) questionnaire used in the United States, translated and validated for Brazil24. The question used was: "In the past seven days, on how many days were you physically active for at least 60 minutes a day?" (Consider moderate to vigorous physical activity). Response options were: 1) no day 2) one day 3) two days 4) three days 5) four days 6) five days 7) six days 8) seven days. Adolescents who practiced physical activity five days or more in the week were classified as "physically active" ( $\geq 300$ minutes per week) and less than five days/week as "physically inactive" $(<300 \text { minutes per week })^{22,25}$.

The eating habits of students were analyzed from the item that integrates the Fantastic Life Style Questionnaire, translated and validated for Brazil ${ }^{26}$. The item had the following sentence: "Do I eat a balanced diet?" This item presented as answer options: 1) almost never 2) rarely 3) sometimes 4 ) with relative frequency and 5) almost always. It was considered as "adequate diet" who answered options 4 or 5 and the other options (1,2 and 3) were classified as "inadequate diet". The instrument presents an explanation of what is a balanced diet with different portions of grains, cereals, fruits, vegetables, dairy products, meats and the like, depending on the age group of the adolescent.

\section{Statistical analysis}

Initially, descriptive analysis (means, standard deviation, and frequency distribution) was performed. To estimate differences in the prevalence of sedentary behavior during school recess according to independent variables, the chi-square test of heterogeneity was applied. Binary logistic regression was used to examine the associations between outcome and socio-demographic factors (sex, age, economic level and type of school), anthropometric indicators (BMI and waist circumference) and lifestyle (physical activity and habits diet), estimating odds ratio (OR) and 95\% confidence interval ( $95 \%$ $\mathrm{CI}$ ). In the adjusted analysis, all variables were introduced into the model, regardless of the p-value in the crude analysis. In the adjusted analysis, variables with a $p$-value $\leq 0.20$ remained, according to the backward method. The significance level was set at 5\%. Analyses were performed in the Statistical Package for the Social Sciences software (IBM SPSS Statistics, Chicago, USA), version 22.0.

\section{Results}

A total of 583 adolescents with a mean age of $13.97 \pm 2.07$ years participated in the study, the majority being female $(51.5 \%)$, in the age group of $14-17$ years $(57.8 \%)$, of the low economic level $(51.6 \%)$ and enrolled in public schools (67.4\%). For waist circumference, 579 evaluations were considered, with five losses due to failure to carry out the measurements, and for the type of school, there was a sample loss, as it was not possible to obtain the adolescent's response in the questionnaire. The prevalence of obesity estimated by BMI was $64.8 \%$ and the prevalence of abdominal obesity estimated by waist circumference was $63.3 \%$. In addition, the majority of adolescents did not meet recommendations of physical activity $(89.7 \%)$ and had inadequate eating habits ( $84.2 \%)$. The prevalence of sedentary behavior in the school recess for the total sample was $50.6 \%(n=295)$, $44.5 \%(n=126)$ for boys and $56.7 \%(n=169)$ for girls (Table 1$)$.

Among male students, the highest prevalence of sedentary behavior in school recess was among those aged 14-17 (50\%) and enrolled in public schools (50.6\%). Among female students, 
the highest prevalence of sedentary behavior in school recess was among those aged $14-17$ years $(65.7 \%)$ and normal waist circumference (64.4\%) (Table 1).

When analyzing the sample without stratifying by sex, the crude analysis showed that students in the age group 14-17 years (OR: $1.48,95 \%$ CI: $0.34-0.67$ ), from private schools (OR: $1.72 ; 95 \%$ CI $\%: 1.21-2.44$ ) and high waist circumference (OR: $1.40,95 \%$ CI: 1.01-1.97) were more likely of remaining in sedentary behavior during school recess when compared to students from public schools and with normal waist circumference, respectively. The adjusted analysis showed that students from private schools (OR: 2.44, 95\% CI: 1.65-3.61) and with inadequate eating habits (OR: $1.62,95 \%$ CI: $1.01-2.62$ ) were more likely of having sedentary behavior in school recess when compared to students from public schools and with adequate eating habits, respectively (Table 2).

When stratifying by sex, the crude analysis showed that, for males, students aged $14-17$ years (OR: $1.66,95 \%$ CI: 1.02-2.67) and from private schools (OR: $1.98,95 \%$ CI: 1.20-3.28) were more likely of remaining in sedentary behavior in the school recess when compared to students aged 11-13 years and from public schools, respectively. In the adjusted analysis, these associations remained, and students aged $14-17$ years (OR: 2.11, 95\% CI: $1.26-3.53$ ) and from private schools (OR: $2.55,95 \% \mathrm{CI}$ : 1.49-4.37) were more likely of remaining in sedentary during school recess when compared to students aged 11-13 years and from public schools, respectively (Table 2).

Table 1. Sample distribution according to sedentary behavior during school recess of students, Criciúma, Santa Catarina, Brazil.

\begin{tabular}{|c|c|c|c|c|c|c|c|c|c|c|c|c|}
\hline \multirow{2}{*}{ Variables* } & \multirow{2}{*}{$\frac{\text { Sample }}{n(\%)}$} & \multicolumn{2}{|c|}{$\begin{array}{l}\text { Sedentary behavior } \\
\text { in school recess }\end{array}$} & \multirow[b]{2}{*}{$\mathbf{p}$} & \multirow{2}{*}{ Male } & \multicolumn{2}{|c|}{$\begin{array}{c}\text { Sedentary behavior } \\
\text { in school recess }\end{array}$} & \multirow[b]{2}{*}{$\mathbf{p}$} & \multirow{2}{*}{ Female } & \multicolumn{2}{|c|}{$\begin{array}{l}\text { Sedentary behavior } \\
\text { in school recess }\end{array}$} & \multirow[b]{2}{*}{$\mathbf{p}$} \\
\hline & & $\begin{array}{c}\text { Yes n } \\
(\%) \\
\end{array}$ & $\begin{array}{l}\text { No n } \\
(\%)\end{array}$ & & & $\begin{array}{c}\text { Yes n } \\
(\%) \\
\end{array}$ & $\begin{array}{l}\text { No n } \\
(\%)\end{array}$ & & & $\begin{array}{c}\text { Yes n } \\
(\%) \\
\end{array}$ & $\begin{array}{c}\text { No n } \\
(\%)\end{array}$ & \\
\hline Total & $\begin{array}{c}583 \\
(100)\end{array}$ & $\begin{array}{c}295 \\
(50.6)\end{array}$ & $\begin{array}{c}287 \\
(49.4)\end{array}$ & & $283(48.5)$ & $\begin{array}{c}126 \\
(44.5)\end{array}$ & $\begin{array}{c}157 \\
(55.5)\end{array}$ & & $300(51.5)$ & $\begin{array}{c}169 \\
(56.7)\end{array}$ & $\begin{array}{c}130 \\
(43.3)\end{array}$ & \\
\hline Age & & & & $<0.01$ & & & & 0.03 & & & & $<0.01$ \\
\hline $11-13$ years & $\begin{array}{c}246 \\
(42.2)\end{array}$ & $99(40.2)$ & $\begin{array}{c}147 \\
(59.8)\end{array}$ & & $125(44.2)$ & 47 (37.6) & $78(62.4)$ & & $121(40.3)$ & $52(43.0)$ & $69(57.0)$ & \\
\hline $14-17$ years & $\begin{array}{c}337 \\
(57.8)\end{array}$ & $\begin{array}{c}196 \\
(58.3)\end{array}$ & $\begin{array}{c}140 \\
(41.7)\end{array}$ & & $158(55.8)$ & $79(50.0)$ & $79(50.0)$ & & $179(59.7)$ & $\begin{array}{c}117 \\
(65.7)\end{array}$ & $61(34.3)$ & \\
\hline Economic level & & & & 0.41 & & & & 0.44 & & & & 0.79 \\
\hline Low & $\begin{array}{c}301 \\
(51.6)\end{array}$ & $\begin{array}{c}157 \\
(52.3)\end{array}$ & $\begin{array}{c}143 \\
(47.7)\end{array}$ & & $141(49.8)$ & $66(46.8)$ & $75(53.2)$ & & $160(53.3)$ & $91(57.2)$ & $68(42.8)$ & \\
\hline High & $\begin{array}{c}282 \\
(48.4)\end{array}$ & $\begin{array}{c}138 \\
(48.9)\end{array}$ & $\begin{array}{c}144 \\
(51.1)\end{array}$ & & $142(50.2)$ & $60(42.3)$ & $82(57.7)$ & & $140(46.7)$ & $78(55.7)$ & $62(44.3)$ & \\
\hline School & & & & $<0.01$ & & & & $<0.01$ & & & & 0.18 \\
\hline Public & $\begin{array}{c}393 \\
(67.4)\end{array}$ & $\begin{array}{l}216 \\
(55.1)\end{array}$ & $\begin{array}{c}176 \\
(44.9)\end{array}$ & & $180(63.6)$ & $91(50.6)$ & $89(49.4)$ & & $212(70.9)$ & $\begin{array}{c}125 \\
(59.0)\end{array}$ & $87(41.0)$ & \\
\hline Private & $\begin{array}{c}190 \\
(32.6)\end{array}$ & $79(41.6)$ & $\begin{array}{c}111 \\
(58.4)\end{array}$ & & $103(36.4)$ & $35(34.0)$ & $68(66.0)$ & & $87(29.1)$ & $44(50.6)$ & $43(49.4)$ & \\
\hline Body Mass Index & & & & 0.08 & & & & 0.26 & & & & 0.28 \\
\hline Normal weight & $\begin{array}{c}378 \\
(64.8)\end{array}$ & $\begin{array}{c}201 \\
(53.3)\end{array}$ & $\begin{array}{c}176 \\
(46.7)\end{array}$ & & $174(61.5)$ & $82(47.1)$ & $92(52.9)$ & & $204(68.0)$ & $\begin{array}{c}119 \\
(58.6)\end{array}$ & $84(41.4)$ & \\
\hline Overweight & $\begin{array}{c}205 \\
(35.2)\end{array}$ & $94(45.9)$ & $\begin{array}{c}111 \\
(54.1)\end{array}$ & & $109(38.5)$ & $44(40.4)$ & $65(59.6)$ & & $96(32.0)$ & $50(52.1)$ & $46(47.9)$ & \\
\hline $\begin{array}{l}\text { Waist } \\
\text { circumference }\end{array}$ & & & & 0.04 & & & & 0.79 & & & & $<0.01$ \\
\hline Normal & $\begin{array}{c}368 \\
(63.6)\end{array}$ & $\begin{array}{c}197 \\
(53.5)\end{array}$ & $\begin{array}{c}171 \\
(46.5)\end{array}$ & & $194(68.8)$ & $85(43.8)$ & $\begin{array}{c}109 \\
(56.2)\end{array}$ & & $174(58.6)$ & $\begin{array}{c}112 \\
(64.4)\end{array}$ & $62(35.6)$ & \\
\hline High & $\begin{array}{c}211 \\
(36.4)\end{array}$ & $95(45.0)$ & $\begin{array}{c}116 \\
(55.0)\end{array}$ & & $88(31.2)$ & $40(45.5)$ & $48(54.5)$ & & $123(41.4)$ & $55(44.7)$ & $68(55.3)$ & \\
\hline Physical activity & & & & 0.28 & & & & 0.09 & & & & 0.81 \\
\hline $\begin{array}{l}\text { Meet } \\
\text { recommendations }\end{array}$ & $\begin{array}{c}60 \\
(10.3)\end{array}$ & $26(44.1)$ & $33(55.9)$ & & $253(89.4)$ & $09(30.0)$ & $21(70.0)$ & & $30(10.0)$ & $17(58.6)$ & $12(41.4)$ & \\
\hline $\begin{array}{l}\text { Does not meet } \\
\text { recommendations }\end{array}$ & $\begin{array}{c}523 \\
(89.7)\end{array}$ & $\begin{array}{c}269 \\
(51.4)\end{array}$ & $\begin{array}{c}254 \\
(48.6)\end{array}$ & & $30(10.6)$ & $\begin{array}{c}117 \\
(46.2)\end{array}$ & $\begin{array}{c}136 \\
(53.8)\end{array}$ & & $270(30.0)$ & $\begin{array}{c}152 \\
(56.3)\end{array}$ & $\begin{array}{c}118 \\
(43.7)\end{array}$ & \\
\hline Eating habits & & & & 0.32 & & & & 0.56 & & & & 0.07 \\
\hline Adequate & $\begin{array}{c}92 \\
(15.8)\end{array}$ & $51(55.4)$ & $41(44.6)$ & & $42(14.8)$ & $17(40.5)$ & $25(59.5)$ & & $50(16.7)$ & $34(68.0)$ & $16(32.0)$ & \\
\hline Inadequate & $\begin{array}{c}491 \\
(84.2) \\
\end{array}$ & $\begin{array}{c}244 \\
(49.8) \\
\end{array}$ & $\begin{array}{c}246 \\
(50.2)\end{array}$ & & $241(85.2)$ & $\begin{array}{c}109 \\
(45.2)\end{array}$ & $\begin{array}{c}132 \\
(54.8)\end{array}$ & & $250(83.3)$ & $\begin{array}{c}135 \\
(54.2) \\
\end{array}$ & $\begin{array}{c}114 \\
(45.8)\end{array}$ & \\
\hline
\end{tabular}

Heterogeneity Chi-square test. 


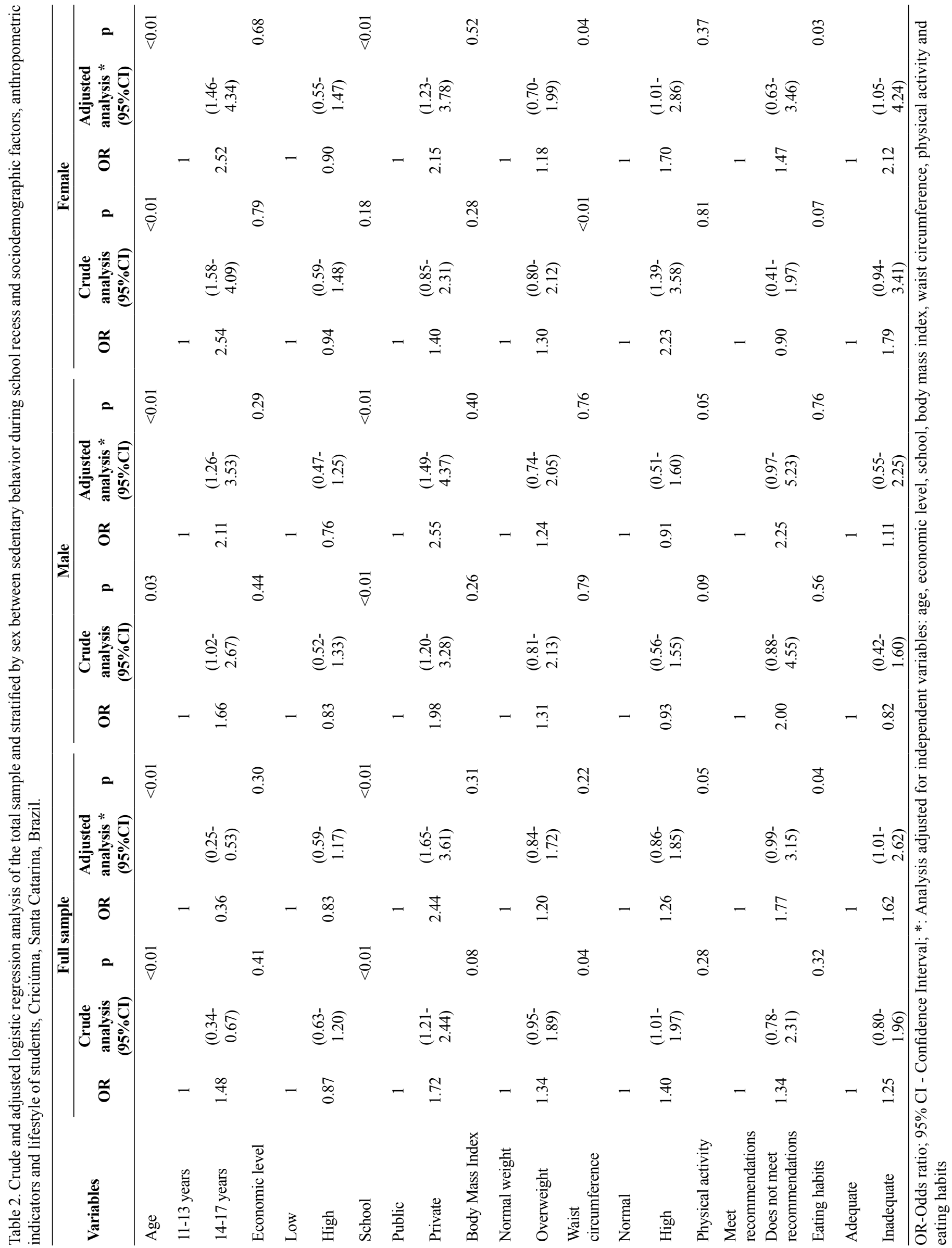


For females, the crude analysis showed that girls aged 1417 years (OR: 2.54, 95\% CI: 1.58-4.09) and with high waist circumference (OR: 2.23 ; 95\% CI: 1.39-3.58) were more likely of remaining in sedentary behavior during school recess when compared to those aged 11-13 years and with the normal waist circumference, respectively. In the adjusted analysis, adolescents aged 14-17 years (OR: 2.52, 95\% CI: 1.46-4.34), from private schools (OR: 2.15, 95\% CI: 1.23-3.78), with high waist circumference (OR: 1.70, 95\% CI: 1.01-2.86) and with inadequate eating habits (OR: 2.12 ; 95\% CI: 1.05-4.24) were more likely of remaining in sedentary behavior during school recess when compared to those aged 11-13 years, from public schools with normal waist circumference and adequate eating habits, respectively (Table 2).

\section{Discussion}

The main findings of this study were: 1) half of adolescents $(50.6 \%)$ presented sedentary behavior during school recess, being this prevalence higher in females $(56.7 \%)$ than in males $(48.5 \%) ; 2$ ) adolescents aged $14-17$ years from private schools and with inadequate eating habits were more likely of remaining in sedentary behavior during school recess. When stratifying by sex, the subgroups most likely of remaining in sedentary behavior during school recess were identified, and the main findings were: 1) male adolescents aged 14-17 years and those from private schools were more likely of remaining in sedentary behavior during school recess; 2) female adolescents aged 1417 years from private schools, with high waist circumference and inadequate eating habits were more likely of remaining in sedentary behavior during school recess.

In the present study, the prevalence of adolescents with sedentary behavior during school recess was 50.6\%. Similar results were found in surveys conducted in different regions of Brazil. A study conducted with 973 students aged 10-19 years of elementary and high schools of Aracaju - Sergipe (SE) found a prevalence of sedentary behavior during the school recess of $58.2 \%{ }^{12}$. A survey with 455 students (aged 8-17 years) from the city of Londrina - Paraná (PR) found a prevalence of sedentary behavior during the school recess of $40.7 \%{ }^{15}$.

In the present study, female adolescents were more likely of remaining in sedentary when compared to males. Previous studies have found similar results in which girls were more likely of remaining in sedentary during school recess. A possible justification for the findings lies in the greater engagement of girls in more sedentary activities during school recess, such as group conversations. Girls appear to present greater barriers to the practice of physical activity such as demotivation, jokes, and insults from boys ${ }^{12,15}$. Moreover, girls lack interest in practicing physical activities may be related to aspects of aesthetics, such as avoiding sweating ${ }^{11}$.

The results of the present study identified that male and female adolescents aged 14-17 years were more likely of remaining in sedentary behavior during school recess when compared to adolescents aged 11-13 years. A similar result was observed in a study conducted in the city of Londrina (PR) with
455 students aged 8-17 years, in which older students (13-17 years) were more likely of remaining in sedentary behavior during school recess when compared to younger adolescents, suggesting that there is a reduction in active behavior during school recess in the transition from childhood to adolescence ${ }^{27}$. Older adolescents spend more time on sedentary on-screen behaviors and less time practicing physical activities compared to younger ones. A possible justification for these findings is that older adolescents have greater access to the internet, such as social networks and online games, when compared to younger adolescents ${ }^{7}$. In addition, with advancing age, adolescents assume greater responsibilities/obligations ${ }^{28}$ and feel less attracted to physical activities ${ }^{6}$.

The results of the present study demonstrated that male and female adolescents from private schools were more likely of remaining in sedentary behavior during school recess. Studies with adolescents have found similar results ${ }^{6,18}$. A possible justification for such finding is that most adolescents from private schools have greater access to technological means such as the use of cell phones, tablets, computers and video games due to the greater purchasing power of families, and these electronics increase the probability of sedentary behavior in leisure time ${ }^{6}$.

Girls with high waist circumference were more likely of remaining in sedentary behavior during school recess. A previous study identified that the time spent on sedentary activities was associated with larger waist circumference ${ }^{8}$. A possible justification for these findings may be the fact that adolescents presented a higher prevalence of consumption of ultra-processed foods, with high-fat content and low nutritive value, contributing to the increase of excess abdominal fat ${ }^{5}$. This explanation is strengthened by the findings of the present study, in which girls with inadequate eating habits were also more likely of remaining in sedentary behavior during school recess. The association between sedentary behavior and inadequate eating habits has already been highlighted in a systematic review ${ }^{29}$. In this sense, the prevention of sedentary behavior in the school recess can help reduce inappropriate eating habits and, consequently, waist circumference.

This study presents limitations such as the use of subjective measures (questionnaires) that may present memory bias. Another limitation was that it did not evaluate the stage of sexual maturation of adolescents, since it is a variable that can influence nutritional assessment, being associated with overweight ${ }^{30}$. The cross-sectional design of the study is another limitation because it does not allow establishing causal relations between variables. In addition, other factors related to the school environment, such as the presence of sports courts, weekly number of Physical Education classes, and physical activity options in the school shifts may be associated with sedentary behavior during the school period that were not investigated in the present study ${ }^{27}$.

On the other hand, the study sample is representative of adolescents from the city of Criciúma, whose results add information about the sedentary behavior of adolescents during school recess. The investigation of different socio-demographic variables, anthropometric and lifestyle indicators in a single analysis model allows greater compression of groups most 
affected by sedentary behavior during school recess and may be strength of this study. In addition, a large part of studies investigated the total time in sedentary behavior, screen time or levels of physical activity during school recess and few studies aimed to investigate sedentary behavior during school recess.

It was concluded that half of the adolescents investigated presented sedentary behavior during school recess, and this prevalence was higher in females than in males. Adolescents aged 14-17 years and those from private schools of both sexes were more likely of remaining in sedentary behavior during school recess, as well as female adolescents with high waist circumference and with inadequate eating habits. Thus, these results can be used to identify subgroups with higher chances of sedentary behavior during school recess, with the purpose of directing intervention strategies in the school environment in an attempt to provide opportunities for the practice physical activities for these adolescents.

\section{References}

1. Pate RR, O'neill JR, Lobelo F. The evolving definition of "sedentary." Exerc Sport Sci Rev. 2008; 36 (4): 173-178. DOI: 10.1097/ JES.0b013e3181877d1a

2. Tremblay MS, Aubert S, Barnes JD, Saunders TJ, Carson V, Latimer-Cheung AE, et al. Sedentary behavior research network (SBRN) - terminology consensus project process and outcome. Int J Behav Nutr Phys Act. 2017; 14 (1): 75-92. DOI: 10.1186/ s12966-017-0525-8

3. LeBlanc AG, Spence JC, Carson V, Connor Gorber S, Dillman C, Janssen I, et al. Systematic review of sedentary behaviour and health indicators in the early years (aged 0-4 years). Appl Physiol Nutr Metab. 2012; 37 (4): 753-772. DOI: 10.1139/h2012-063

4. Tremblay MS, LeBlanc AG, Kho ME, Saunders TJ, Larouche R, Colley RC, et al. Systematic review of sedentary behaviour and health indicators in school-aged children and youth. Int J Behav Nutr Phys Act. 2011; 8 (1): 98-120. DOI: 10.1186/1479-5868-8-98

5. Costa C dos S, Flores TR, Wendt A, Neves RG, Assunção MCF, Santos IS. Comportamento sedentário e consumo de alimentos ultraprocessados entre adolescentes brasileiros: Pesquisa Nacional de Saúde do Escolar (PeNSE), 2015. Cad Saude Publica. 2018; 34 (3): 1-12. DOI: 10.1590/0102-311X00021017

6. Dias PJP, Domingos IP, Ferreira MG, Muraro AP, Sichieri R, Gonçalves-Silva RMV. Prevalência e fatores associados aos comportamentos sedentários em adolescentes. Rev Saúde Pública. 2014; 48 (2): 266-274. DOI: 10.1590/S0034-8910.2014048004635Rev

7. Ferreira RW, Rombaldi AJ, Ricardo LIC, Hallal PC, Azevedo MR. Prevalência de comportamento sedentário de escolares e fatores associados. Rev Paul Pediatr. 2016; 34 (1): 56-63. DOI: 10.1016/j. rpped.2015.06.005

8. Cooper AR, Sebire S, Montgomery AA, Peters TJ, Sharp DJ, Jackson $\mathrm{N}$, et al. Sedentary time, breaks in sedentary time and metabolic variables in people with newly diagnosed type 2 diabetes. Diabetologia. 2012; 55 (3): 589-599. DOI: 10.1007/s00125-011-2408-x

9. Healy GN, Dunstan DW, Salmon J, Cerin E, Shaw JE, Zimmet PZ, et al. Breaks in sedentary time: beneficial associations with metabolic risk. Diabetes Care. 2008; 31 (4): 661-666. DOI: 10.2337/dc07-2046
10. Martinez-Gomez D, Tucker J, Heelan KA, Welk GJ, Eisenmann JC. Associations between sedentary behavior and blood pressure in young children. Arch Pediatr Adolesc Med. 2009; 163 (8): 724-730. DOI: 10.1001/archpediatrics.2009.90

11. Faria FR, Canabrava KR, Amorim PR. Nível de atividade física durante o recreio escolar em escola pública e particular. Rev Bras Ciênc e Mov. 2013; 21 (1): 90-97. DOI: 10.1007/s00125-011-2408-x

12. Silva DAS, dos Santos Silva RJ, Petroski EL. Comportamento sedentário no recreio escolar e fatores sociodemográficos associados. J Phys Educ. 2010; 21 (2): 255-261. DOI: 10.4025/reveducfis.v21i2.8321

13. Hohepa M, Scragg R, Schofield G, Kolt GS, Schaaf D. Self-reported physical activity levels during a segmented school day in a large multiethnic sample of high school students. J Sci Med Sport. 2009; 12 (2): 284-292. DOI: 10.1016/j.jsams.2007.11.005

14. Stratton G, Ridgers ND, Fairclough SJ, Richardson DJ. Physical Activity Levels of Normal-weight and Overweight Girls and Boys During Primary School Recess. Obesity. 2007; 15 (6): 1513-1519. DOI: $10.1038 /$ oby.2007.179

15. Greca JP de A, Silva DAS. Sedentary behavior during school recess in southern Brazil. Percept Mot Skills. 2017; 124 (1): 105-117. DOI: $10.1177 / 0031512516681693$

16. Nunes HEG, de Andrade Gonçalves EC, Vieira JAJ, Silva DAS. Clustering of risk factors for non-communicable diseases among adolescents from Southern Brazil. PloS One. 2016; 11 (7): 1-13. DOI: 10.1371 journal.pone.0159037

17. Sousa GR de, Silva DAS. Sedentary behavior based on screen time: prevalence and associated sociodemographic factors in adolescents. Cienc Saude Coletiva. 2017; 22 (12): 4061-4072. DOI: 10.1590/1413-812320172212.00472016

18. Werneck AO, Oyeyemi AL, Fernandes RA, Romanzini M, Ronque ER, Cyrino ES, et al. Regional Socioeconomic Inequalities in Physical Activity and Sedentary Behavior Among Brazilian Adolescents. J Phys Act Health. 2018; 15 (5): 338-344. DOI: 10.1123/jpah.2017-0338

19. de Oliveira G, Silva DAS, Maggi RM, Petroski EL, de Farias JM. Fatores sociodemográficos e de aptidão física associados à baixos níveis de atividade física em adolescentes de uma cidade do Sul do Brasil. J Phys Educ. 2012; 23 (4): 635-645. DOI: 10.4025/ reveducfis.v23i4.17510

20. Silva DAS, Teixeira DM, De Oliveira G, Petroski EL, de Farias JM. Aerobic fitness in adolescents in southern Brazil: Association with sociodemographic aspects, lifestyle and nutritional status. Rev Andal Med Deporte. 2016; 9 (1): 17-22. DOI: 10.1016/j. ramd.2014.11.002

21. Guedes DP, Guedes JERP. Medida da Atividade Física em Jovens Brasileiros: Reprodutibilidade e Validade do PAQ-C e do PAQ-A. Rev Bras Med Esporte. 2015; 21 (6): 425-432. DOI: 10.1590/1517-869220152106147594

22. Onis M de, Onyango AW, Borghi E, Siyam A, Nishida C, Siekmann J. Development of a WHO growth reference for school-aged children and adolescents. Bull World Health Organ. 2007; 85: 660-667. DOI: 10.2471/BLT.07.043497

23. Taylor RW, Jones IE, Williams SM, Goulding A. Evaluation of waist circumference, waist-to-hip ratio, and the conicity index as screening tools for high trunk fat mass, as measured by dual-energy X-ray absorptiometry, in children aged 3-19 y-. Am J Clin Nutr. 2000; 72 (2): 490-495. DOI: 10.1093/ajen/72.2.490 
24. Guedes DP, Lopes CC. Validação da versão brasileira do youth risk behavior survey 2007. Rev Saúde Pública. 2010; 44 (5): 840-850. DOI: $10.1590 / \mathrm{S} 0034-89102010000500009$

25. Strong WB, Malina RM, Blimkie CJ, Daniels SR, Dishman RK, Gutin B, et al. Evidence based physical activity for school-age youth. J Pediatr. 2005; 146 (6): 732-737. DOI: 10.1016/j.jpeds.2005.01.055

26. Añez CRR, Reis RS, Petroski EL. Versão brasileira do questionário "Estilo de Vida Fantástico": tradução e validação para adultos jovens. Arq Bras Cardiol. 2008; 91 (2): 102-9. DOI: 10.1590/ S0066-782X2008001400006

27. Silva DAS, Chaput J-P, Katzmarzyk PT, Fogelholm M, Hu G, Maher C, et al. Physical Education Classes, Physical Activity, and Sedentary Behavior in Children. Med Sci Sports Exerc. 2018; 50 (5): 995-1004. DOI: 10.1249/MSS.0000000000001524

28. Greca JP de A, Silva DAS, Loch MR. Physical activity and screen time in children and adolescents in a medium size town in the South of Brazil. Rev Paul Pediatr. 2016; 34 (3): 316-322. DOI: 10.1016/j.rppede.2016.01.001

29. Guerra PH, Cazuza de Farias Júnior J, Florindo AA. Comportamento sedentário em crianças e adolescentes brasileiros: revisão sistemática. Rev Saúde Pública. 2016; 50. DOI: 10.1590/ S1518-8787.2016050006307
30. de Oliveira JR, Frutuoso MFP, Gambardella AMD. Associação entre maturação sexual, excesso de peso e adiposidade central em crianças e adolescentes de duas escolas de São Paulo. J Hum Growth Dev. 2014; 24 (2): 201-207. DOI: 10.7322/jhgd.81230

\section{Corresponding author}

Diego Augusto Santos Silva

Federal University of Santa Catarina, University Campus, Trindade, Physical Educacion Departament. Zip code: 476, CEP 88040-900, Florianópolis, Santa Catarina, Brazil.

E-mail: diegoaugustoss@yahoo.com.br

Manuscript received on July 10, 2018

Manuscript accepted on August 22, 2018

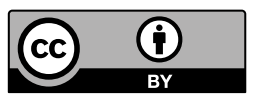

Motriz. The Journal of Physical Education. UNESP. Rio Claro, SP, Brazil - eISSN: 1980-6574 - under a license Creative Commons - Version 3.0 